\title{
PROCESSO FENTON NO TRATAMENTO E REMEDIAÇÃO DA AREIA DE FUNDIÇÃO
}

\section{L.A.D. KOSLOWSKI ${ }^{1}$, V. C. COLONETTI ${ }^{1}$, S. LICODIEDOFF ${ }^{1}$, H.G. RIELLA ${ }^{1}$, S.L. BERTOLI ${ }^{2}$, E.L.SIMIONATTO ${ }^{3}$}

${ }^{1}$ Universidade Federal de Santa Catarina, Departamento de Engenharia Química e Engenharia de Alimentos

${ }^{2}$ Universidade Regional de Blumenau-FURB, Departamento de Engenharia Química

${ }^{3}$ Universidade Regional de Blumenau-FURB, Departamento de Química

E-mail para contato: lucianoandre@yahoo.com

RESUMO - A areia constitui o principal resíduo no processo de fundição, uma vez que é utilizada na confecção dos moldes, tornando a indústria de fundição altamente poluidora. A disposição deste resíduo em aterros industriais provoca um sério problema ambiental e exige altos investimentos. Este trabalho visa estudar o processo de regeneração da areia de fundição contaminada com resina fenólica através de tratamento químico utilizando um processo de oxidação avançado. As condições da reação de Fenton avaliaram a degradação dos poluentes presentes na areia de fundição. Os parâmetros empregados no processo de regeneração da areia foram: concentração de peróxido de hidrogênio, sal de ferro (II), $\mathrm{pH}$, temperatura e tempo de reação. O planejamento fatorial utilizado indicou que a melhor condição para a reação de oxidação Fenton é aquela que combina as três variáveis de estudo: concentração de peróxido de hidrogênio: $900 \mathrm{mg} \cdot \mathrm{L}^{-1}$, concentração do sal de ferro: $600 \mathrm{mg} \cdot \mathrm{L}^{-1}$ e $\mathrm{pH} 3,0$.

\section{INTRODUÇÃO}

Nas últimas décadas, o setor industrial tem dedicado um esforço intenso na melhoria dos processos de fabricação, buscando melhorar a qualidade do produto acabado e aumentar a competitividade no mercado industrial. $\mathrm{O}$ descarte de resíduos industriais e urbanos no ar, na água e no solo tem sido de grande preocupação na atualidade, pois este vem sendo depositado em aterros por muitas indústrias de forma inadequada (Lora, 2000).

Os rejeitos industriais, materiais industriais de processo produtivo de qualquer indústria, podem ser reciclados dentro do próprio processo (regeneração), tratados e classificados para serem utilizados como insumos em outros processos e produtos (reciclados) ou tratados em rejeitos que devem receber tratamento adequado para evitar sua transformação em contaminantes (Mariotto, 2003). Conforme Ayolla (2010), um dos rejeitos que tem causado preocupação pelos danos acarretados ao meio ambiente é a areia descartada no processo de fundição.

As areias de fundição normalmente são classificadas como Resíduos Classe II (atualmente considerada Classe IIA) da Associação Brasileira de Normas Técnicas ABNT, 


\section{9 a 22 de outubro de 2014 \\ Florianópolis/SC}

através da NBR 10.004, ou seja, não inertes e, portanto, com possibilidade de agressão ao meio ambiente (Bonin et al., 1995).

O principal componente da areia de fundição é a conhecida como "areia base", sendo o tipo mais empregado a areia de sílica $\left(\mathrm{SiO}_{2}\right)$, devido a sua facilidade de extração, formato arredondado, tamanho de partícula que permitem uma compactação mais eficiente e menor quantidade de aglomerante para atingir uma dada resistência (Rampazzo, 1989). A areia de fundição descartada constitui uma mistura de areias utilizadas nos moldes e machos, que incluem descartes da areia de formação da caixa de moldagem e da areia de moldagem dos machos. Durante algumas etapas do processo podem ser misturadas com as areias provenientes do acabamento das peças, ou seja, das rebarbas provenientes de peças fundidas e do jato de areia de limpeza superficial das mesmas (Bonin et al., 1997).

Os processos de oxidação avançados (POA'S) têm como objetivo a destruição de compostos orgânicos estáveis presentes nos rejeitos dos processos industriais. $\mathrm{O}$ reagente de Fenton é uma mistura fortemente oxidante de peróxido de hidrogênio e sal de ferro (II) que atua como catalisador. Neste processo os radicais hidroxilas são formados in situ e são capazes de oxidar substâncias tóxicas e recalcitrantes. O reagente de Fenton é empregado como agente oxidante em sínteses orgânicas. Sua aplicação é bastante promissora, pois sais de ferro agem como catalisadores para a decomposição do peróxido de hidrogênio (Kang e Hwang, 2000).

O controle do $\mathrm{pH}$ é um dos fatores que afetam a taxa de degradação, e em condições ácidas, pH próximo de 2,8, a reação de Fenton é fortemente favorecida. Muitas estudos referenciam temperaturas de operação na faixa de $20-50^{\circ} \mathrm{C}$. Entretanto, para temperaturas acima de $40^{\circ} \mathrm{C}$ a eficiência de utilização do peróxido de hidrogênio diminui devido a decomposição acelerada do peróxido de hidrogênio em água e oxigênio (Vinodgopal e Peller, 1998).

A razão ótima de $\mathrm{H}_{2} \mathrm{O}_{2}$ /catalisador para a reação de Fenton, em grande parte das aplicações, está na proporção de 10:1 a 40:1 (Kang, 2006). Em geral, grandes quantidades de ferro na solução produzem aumento na velocidade de degradação, porém o uso de grandes quantidades de ferro (II) na solução tem um efeito negativo, pois se torna necessário uma etapa adicional no processo para a remoção dos íons ferrosos (Peña, 2003). Deste modo, o presente trabalho tem como objetivo avaliar o grau de eficiência da reação de Fenton no processo de regeneração da areia de fundição.

\section{MATERIAIS E MÉTODOS}

\subsection{Materiais}

A areia de fundição de descarte utilizada foi proveniente de uma empresa de fundição localizada no município de Joinville, Santa Catarina, Brasil. O resíduo coletado corresponde à mistura do processo produtivo desde o processo de moldagem até a quebra de canal e rebarbação. A coleta seguiu as normas da NBR 10.007/04. O material coletado corresponde ao material final enviado semanalmente ao aterro industrial. 


\subsection{Planejamento Fatorial}

Os ensaios foram realizados utilizando um planejamento fatorial, conforme a Tabela 1, de forma a avaliar a condição mais favorável na remediação de contaminantes presentes na areia de fundição classificada como mistura.

Tabela 1 - Planejamento fatorial para os experimentos

\begin{tabular}{|c|c|c|}
\hline VARIÁ VEL DE ESTUDO & Efeito ( - ) & Efeito (+ ) \\
\hline Potencial Hidrogeniônico & 4,0 & 3,0 \\
\hline Concentração de Sulfato de Ferro II & $300 \mathrm{mg} / \mathrm{L}$ & $600 \mathrm{mg} / \mathrm{L}$ \\
\hline $\begin{array}{c}\text { Concentração de Peróxido de } \\
\text { Hidrogênio }\end{array}$ & $200 \mathrm{mg} / \mathrm{L}$ & $900 \mathrm{mg} / \mathrm{L}$ \\
\hline
\end{tabular}

\subsection{Lixiviação e solubilização}

A areia de fundição proveniente do processo de desmoldagem foi submetida a ensaios de lixiviação de resíduos conforme a NBR 10.005/04. Primeiramente, determinou-se o pH da amostra para empregar a solução correspondente ao ensaio de lixiviação. A amostra pesada foi colocada no jar-test e adicionou-se a solução de lixiviação $(5,7 \mathrm{~mL}$ de ácido acético em $1000 \mathrm{~mL}$ de solução de água deionizada). A agitação foi realizada por 18 horas e em seguida procedeu-se a filtração em filtro de fibra de vidro de $0,7 \mu \mathrm{m}$. No filtrado obtido foram realizados ensaios de espectrofotometria de absorção atômica modo chama e determinação de fenóis pelo método HACH 8047. A solubilização da areia foi realizada com o objetivo de caracterizar os componentes presentes nas amostras coletadas, tanto da areia bruta como da areia de moldagem. A técnica consiste na dissolução de um componente de um resíduo, quando submetido a um contato estático ou dinâmico, com água deionizada à temperatura ambiente conforme a NBR 10.006/04.

\subsection{Reação de Fenton}

Adicionou-se 5 gramas da areia de moldagem em $50 \mathrm{~mL}$ de água deionizada em um béquer cilíndrico de $250 \mathrm{~mL}$. Aqueceu-se a mistura a temperatura limite de $40^{\circ} \mathrm{C}$, recomendada para a reação de Fenton. Ajustou-se o pH da solução entre 3,0 e 4,0 com ácido sulfúrico $10 \%$ como sendo o ideal para a reação. De acordo com Neamtu (2003), este procedimento é necessário para que ocorra a formação de radicais hidroxilas, já que a formação de hidróxido férrico - $\mathrm{Fe}(\mathrm{OH})_{3}$ - reduz a quantidade de catalisador disponível para a reação e decompõe o peróxido de hidrogênio diminuindo a eficiência da reação. Na etapa seguinte, foram adicionados sulfato de ferro II e peróxido de hidrogênio $30 \%$ na proporção estequiométrica de 1:5. Verificou-se o $\mathrm{pH}$ da solução e foi efetuado o ajuste utilizando hidróxido de sódio 1 Molar. Procedeu-se agitação durante as etapas citadas pelo período de 15 minutos e, a seguir, o material foi mantido em repouso durante o período de quatro horas, como mostra a Figura 1. 


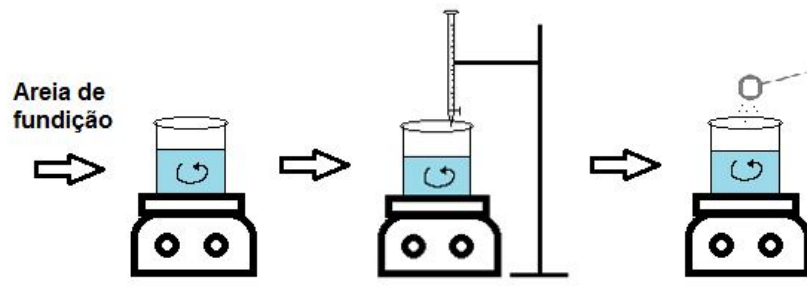

(A)

(B)

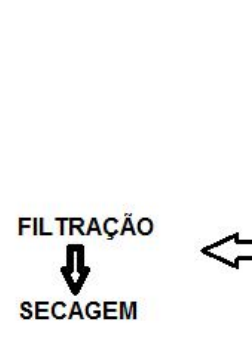

(F)

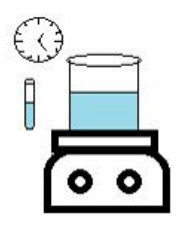

(E)

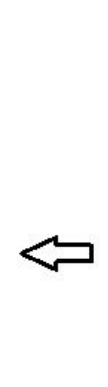

(C)

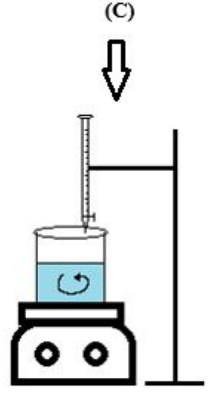

(D)

Figura 1 - Ilustração do experimento de Fenton.

Efetuou-se a filtração em papel filtro de malha $0,8 \mu \mathrm{m}$ e secagem do material em estufa a $70^{\circ} \mathrm{C}$ por um período de 30 minutos. Pesou-se o material a fim de verificar a perda de massa nessa etapa.

\section{RESULTADOS E DISCUSSÃO}

A areia de fundição coletada no final do processo (desmoldagem e quebra de canal) foi submetida ao processo de lixiviação de acordo com a NBR 10.0005/04 e solubilização conforme NBR 10.0006/04, cuja caracterização pode ser observada na Tabela 2.

Tabela 2 - Dados referentes à solubilização/lixiviação da areia de fundição

\begin{tabular}{|c|c|c|c|}
\hline Parâmetros & $\begin{array}{c}\text { Resultados da } \\
\text { Solubilização (NBR } \\
10.006 / 04)\end{array}$ & Parâmetros & $\begin{array}{c}\text { Resultados da } \\
\text { Lixiviação (NBR } \\
10.005 / 04)\end{array}$ \\
\hline Aspecto & $\begin{array}{c}\text { areia fina com } \\
\text { grânulos brancos }\end{array}$ & pH final & 5,0 \\
\hline Cor & preto & $\begin{array}{c}\text { Volume total do } \\
\text { lixiviado }\end{array}$ & $2,0 \mathrm{~L}$ \\
\hline Odor & inodoro & Massa utilizada & $100 \mathrm{~g}$ \\
\hline Umidade & $0,37 \%$ & Coloração & incolor \\
\hline Teor de Sólidos $(\%)$ & 100 & $\begin{array}{c}\text { Tempo total de } \\
\text { lixiviação }\end{array}$ & $18 \mathrm{~h}$ \\
\hline
\end{tabular}

Os resíduos de fundição caracterizados como areia bruta e a areia resultante da desmoldagem e quebra de canal foram inseridos dentro das listagens 7 e 8 conforme a NBR 10.005/04 e 10.004/04, respectivamente. As Tabelas 3 e 4 apresentam os resultados obtidos e comparativos com a referida norma. 
Tabela 3 - Resultados comparativos dos ensaios de lixiviação com areia bruta e areia (desmoldagem + quebra de canal) conforme listagem 7 - NBR 10.005/04

\begin{tabular}{|c|c|c|c|c|}
\hline Ensaio & \multicolumn{2}{|c|}{ Lixiviação - Areia Bruta } & \multicolumn{2}{c|}{$\begin{array}{c}\text { Lixiviação - Areia (desmoldagem } \\
\text { + quebra de canal) }\end{array}$} \\
\hline Poluente & $\begin{array}{c}\text { Resultado } \\
(\mathrm{ppm})\end{array}$ & $\begin{array}{c}\text { Listagem 7 } \\
(\mathrm{ppm})\end{array}$ & $\begin{array}{c}\text { Resultado } \\
(\mathrm{ppm})\end{array}$ & $\begin{array}{c}\text { Listagem 7 } \\
(\mathrm{ppm})\end{array}$ \\
\hline Alumínio & 1,66 & indisponível & 0,40 & indisponível \\
\hline Bário & 90,30 & $<100$ & 0,93 & $<100$ \\
\hline Cádmio & 0,00001 & $<0,5$ & 0,00001 & $<0,5$ \\
\hline Fenol & 0,080 & $<0,01$ & 0,1480 & $<0,01$ \\
\hline Ferro & nd $^{*}$ & indisponível & 0,093 & indisponível \\
\hline Sulfato $\left(\mathrm{SO}_{4}\right)^{-2}$ & 0,07 & indisponível & 1,0 & indisponível \\
\hline
\end{tabular}

*nd: não detectado

De acordo com a Tabela 3, o extrato lixiviado apresentou, dentre os parâmetros pesquisados da listagem 7 da NBR 10.005/04, concentrações de poluentes próximos aos limites estabelecidos, com exceção da presença de fenol, cuja concentração no lixiviado para a areia proveniente do processo de desmoldagem e quebra de canal foi de $0,148 \mathrm{ppm}$.

O resíduo pode ser classificado como não inerte de CLASSE IIA, sendo, portanto necessário um tratamento adequado para que possa ser enquadrado como de CLASSE IIB Inerte, conforme cita a NBR 10.004/04. A respeito da areia bruta, a mesma apresentou pequena concentração de fenol $(0,08 \mathrm{ppm})$; da mesma forma, encontra-se acima do permitido pela NBR 10.005/04. A justificativa para essa areia apresentar fenol em sua composição, se deve ao fato de que parte da areia proveniente do processo de desmoldagem e quebra de canal é reaproveitada, e ao ser misturado com a areia virgem, acaba contaminando o material.

A areia proveniente da desmoldagem e quebra de canal, tratada através da reação de oxidação de Fenton, foi submetida a um ensaio de lixiviação para posteriormente determinar a concentração de fenol remanescente no resíduo. Como comparativo foi utilizado o valor presente na areia no final do processo sem tratamento de $0,135 \mathrm{mg} \cdot \mathrm{L}^{-1}$. A areia proveniente da quebra de canal tratada através do processo de oxidação de Fenton apresentou uma redução na concentração de fenol, o que evidencia a eficiência do processo, conforme apresentado na Tabela 4.

A areia proveniente da desmoldagem e quebra de canal tratada através do processo de oxidação também apresentou uma redução na concentração de fenol, demonstrando mais uma vez a eficiência do processo. Comparativamente aos ensaios efetuados, verifica-se que a condição mais favorável $\left(\mathrm{pH}=3,0 ;\left[\mathrm{H}_{2} \mathrm{O}_{2}\right]=900 \mathrm{mg} / \mathrm{L}\right.$ e $\left.\left[\mathrm{FeSO}_{4}\right]=600 \mathrm{mg} / \mathrm{L}\right)$ apresenta menor concentração de fenol na areia de desmoldagem e quebra de canal. Os ensaios 6 e 7 apresentaram a menor concentração de fenol na areia de fundição. Isso pode ser explicado através do papel do pH nas reações envolvidas, já que na faixa de 2,5 a 3,0 permite uma máxima eficiência de degradação (Pignatello e Sun, 1995). 
Tabela 4 - Dados comparativos da concentração de fenol presente na areia de desmoldagem + quebra de canal com e sem tratamento de Fenton

\begin{tabular}{|c|c|c|c|c|c|}
\hline Ensaio & $\mathrm{pH}$ & $\begin{array}{c}\text { Concentração } \\
\text { do Peróxido } \\
\text { de Hidrogênio } \\
(\mathrm{mg} / \mathrm{L})\end{array}$ & $\begin{array}{c}\text { Concentração } \\
\text { de Sulfato de } \\
\text { Ferro II } \\
(\mathrm{mg} / \mathrm{L})\end{array}$ & $\begin{array}{c}\text { Concentração } \\
\text { de Fenol (mg/L) }\end{array}$ & $\begin{array}{c}\text { \% de } \\
\text { Degradação } \\
\text { de Fenol }\end{array}$ \\
\hline $\begin{array}{c}\text { Areia sem } \\
\text { tratamento } \\
\text { (quebra de } \\
\text { canal) }\end{array}$ & ---- & --- & --- & 0,135 & - - - \\
\hline 1 & 3,0 & 200,00 & 300,00 & 0,108 & 20.00 \\
\hline 2 & 4,0 & 900,00 & 300,00 & 0,110 & 18.51 \\
\hline 3 & 4,0 & 200,00 & 600,00 & 0,112 & 17.03 \\
\hline 4 & 4,0 & 900,00 & 600,00 & 0,105 & 22.22 \\
\hline 5 & 3,0 & 200,00 & 600,00 & 0,099 & 26.66 \\
\hline 6 & 3,0 & 900,00 & 600,00 & 0,092 & 31.85 \\
\hline 7 & 3,0 & 900,00 & 300,00 & 0,098 & 27.40 \\
\hline 8 & 4,0 & 200,00 & 300,00 & 0,117 & 13.33 \\
\hline
\end{tabular}

A concentração de $\mathrm{H}_{2} \mathrm{O}_{2}$ está relacionada com a eficiência de degradação de fenol presente na areia de fundição. Substratos que são encontrados em fases não aquosas normalmente são pouco atacados por radical hidroxila, devido a limitações ocorridas por transferência de massa. Entretanto, elevadas concentrações de peróxido podem promover a transferência dos radicais hidroxila através da interface sólido-líquido e, promover a oxidação de contaminantes (Flaherty e Huang, 2005). A Tabela 4 e a Figura 2 comprovam que um aumento da concentração de $\mathrm{H}_{2} \mathrm{O}_{2}$ promove uma maior degradação de fenol.

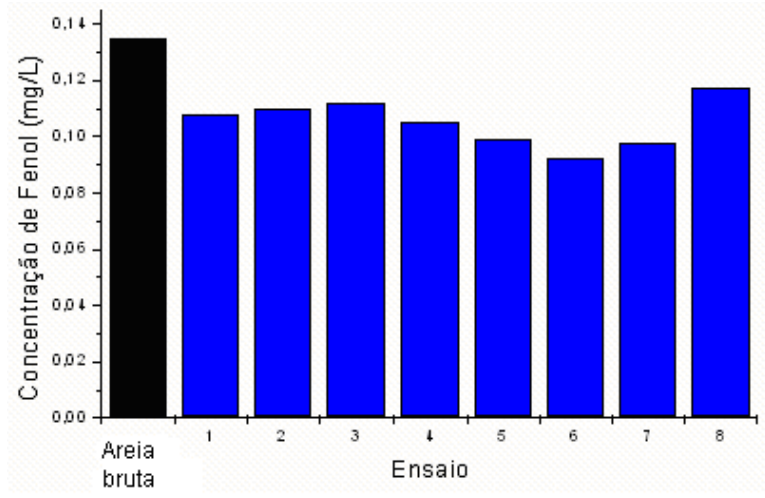

Figura 2 - Concentração de fenol na areia bruta e na areia (desmoldagem + quebra de canal) após a reação de Fenton conforme experimentos da Tabela 4.

A respeito da eficiência do mecanismo de degradação do fenol na reação de Fenton, os valores obtidos indicaram $13,33 \%$ para a pior condição e $31,85 \%$ para a melhor condição. A 
presença de catalisador contribuiu para uma pequena redução da concentração de fenol com um aumento na concentração de sulfato de ferro II. A adição de sais de ferro II permite a formação de radical hidroxila, que é a espécie oxidante capaz de oxidar espécies orgânicas, entre eles, os compostos fenólicos. Entretanto, deve-se ter o cuidado quanto à adição de $\mathrm{H}_{2} \mathrm{O}_{2}$, pois o excesso desse provoca um aumento na concentração de íons férrico $\left(\mathrm{Fe}^{3+}\right)$, cuja concentração é superior a de íons ferroso $\left(\mathrm{Fe}^{2+}\right)$. O íon férrico apresenta uma reação muito mais lenta com $\mathrm{H}_{2} \mathrm{O}_{2}$ comparado a presença de íons ferroso; prejudicando o mecanismo de degradação (Torrades et al., 2002).

\section{CONCLUSÃO}

O melhor conjunto de parâmetros para a reação de oxidação Fenton, é aquela que combina as três variáveis de estudo $(\mathrm{pH}$, concentração de peróxido e sal de ferro II) como efeito positivo na degradação de fenol; ou seja $\mathrm{pH}=3,0$; sal de ferro $=600 \mathrm{mg} / \mathrm{L}$ e peróxido de hidrogênio igual a $900 \mathrm{mg} / \mathrm{L}$. O intervalo de reação aplicado para este estudo mostrou-se ser o mais adequado para uma escala em batelada, sendo entretanto necessário otimizar esta variável em conjunto com as concentrações de catalisador/peróxido no caso de um processo contínuo.

\section{REFERÊNCIAS}

ASSOCIAÇÃO BRASILEIRA DE NORMAS TÉCNICAS. Resíduos sólidos - Classificação: NBR 10.004/04. Rio de Janeiro, 2004.

ASSOCIAÇÃO BRASILEIRA DE NORMAS TÉCNICAS. Lixiviação de Resíduos procedimento: NBR 10.005/04. Rio de Janeiro, 2004.

ASSOCIAÇÃO BRASILEIRA DE NORMAS TÉCNICAS. Solubilização de Resíduos procedimento: NBR 10.006/04. Rio de Janeiro, 2004.

ASSOCIAÇÃO BRASILEIRA DE NORMAS TÉCNICAS. Amostragem de Resíduos procedimento: NBR 10.007/04. Rio de Janeiro, 2004.

AYOOLA, W.A.; ADEOSUN, S.O., OYETUNJI, A. Suitab ility of Oshogbo Sand. Deposit as Moulding Sand. Kenya Journal of Mechanical Engineering, Volume 6(1): 33-4, , 2010.

BONIN, A. L.; MARIOTTO, C.L.; BARTH, F. Regeneração de areias: Relatório de visitas a usuários de sistemas de regeneração de areias de fundição. ABIFA, 1997.

BONIN, A. L.; ROSSINI, A. J.; ZABIM, A. F. P. Reutilização da areia preta de fundição na construção civil. ABIFA, 1995.

FLAHERTY, K. A.; HUANG, C. P. Continuous flow applications of fenton's reagent for the treatment of refractory wastewater apud SCHEUNEMANN, R. Regeneração de areia de fundição através de tratamento químico via processo Fenton. Florianópolis. Universidade Federal de Santa Catarina, p. 71, 2005. 
KANG, Y. W., HWANG, K. Y. 2000 apud EREN, Z.; ACAR, F. N. Effect of Fenton's reagent on the degradability of CI Reactive Yellow 15. Color. Technol., v. 122, n. 5, p. 259263, 2006.

LORA, E. S. Prevenção e controle da poluição nos setores energético, industrial e de transporte. Brasília. ANEEL, 2000.

MARIOTTO, C. L. Regeneração de areia de fundição. IX Congresso de Fundição - CONAF 2003, Instituto de Pesquisas Tecnológicas do estado de São Paulo - SP, 2003.

NEAMTU, M.; YEDILER, A.; SIMINICEANU, I.; KETTRUP, A. Oxidation of commercial reactive azo dye aqueous solutions by the photo-fenton and fenton-like processes. $J$. Photochem. Photobiol., v. 161, n. 1, p. 87-93, 2003.

PEÑA, R.M., et al. Environmental Atmosphere. V.35, p. 209, 2001 e KLAIS, O. Thermochim. Acta, p.213-225, 1993 e FREIRE, R. S., et al Quim. Nova, 23,504, 2000 apud MATTOS, I.L., SHIRAISHI, K. A., BRAZ, A. D., FERNANDES, J. R. Peróxido de Hidrogênio: Importância e Determinação. Química Nova. no. 3, v. 26, p. 373-380, 2003.

PIGNATELLO, J. J.; SUN, Y. Evidence for a sulface dual hole-radical mechanism in the TiO2 photocatalytic oxidation of 2,4-dichlorophenoxiacetic acid. Environ. Sci. Technol., p. 2065, 1995.

RAMPAZZO, D.; JERONYMO, J. R.; BEGALLI, L.; MONTANARI FILHO, P. Resinas sintéticas para fundição. Editora Alba, Itaúna-MG, 1989.

TORRADES, F.; PEREZ, M.; GARCIA-HORTAL, J.A.; DOMENECH, S.; PERAL, J. Removal of organic contaminants in paper pulp treatment effluents by Fenton and photoFenton reactions. Appl. Catal. B-Environ., p. 63-74, 2002. 